\title{
PASTORAL DO MIGRANTE Relações e Mediações
}

\section{Ana Cristina Arantes Nasser e Sidnei Marco Dornelas São Paulo: CEM; Loyola, 2008. 367p.}

O livro é organizado em duas partes. A primeira delas é resultado de trabalhos independentes dos dois autores, mas que se assentam sobre fontes, objeto e metodologia comuns de pesquisa. A segunda é escrita por Sidnei Marco Dornelas. Trata-se de sua dissertação de Mestrado em Teologia Pastoral. Seguem-se dois fartos anexos, também cotejados com uma análise que poderia constituir uma terceira parte.

A tese central dos autores é que o SPM - Serviço Pastoral dos Migrantes, enquanto representante da Pastoral do Migrante - Setor Urbanos, tece um diálogo desencontrado nas suas relações de mediação junto aos migrantes e a Igreja. A fonte desse desencontro teria um duplo caráter: a) a crescente funcionalização, racionalização e opção do SPM em converter uma agenda pastoral teológica em uma agenda global de temas políticos e sociais - mais característica dos movimentos sociais - desarticulada do cotidiano e da "condição social do migrante"; b) uma ação pastoral teologicamente estéril, socialmente enviesada, sem revelar um "lugar hermenêutico seminal". Esta tese é o fio condutor de todo o texto.

Antes de aprofundar esta resenha, avalio ser pertinente explicitar algumas noções conceituais chaves na abordagem dos autores.

A "condição social do migrante" se caracteriza pelo duplo deslocamento do migrante

como emigrante-imigrante, a fidelidade às suas redes de relacionamento, o latente conflito com as outras instituições sociais, os usos dos fragmentos de sua herança religiosa e cultural em função de seus interesses de grupo, e toda relação dúbia e enviesada com os agentes institucionais inclusive aqueles oriundos da Pastoral do Migrante (DORNELAS: 2008, p.236). 
Essa condição altera-se conforme as origens, as gerações, as várias formas de inserção na cidade, o intenso cruzamento de influências culturais e o coloca sempre numa situação de provisoriedade na qual as experiências vividas por ele no seu cotidiano são decisivas para a sua permanência e formas de vida social, cultural e religiosa na cidade.

A condição social do migrante também pode ser apreendida como um "lugar teológico" a partir do encontro do agente de pastoral com o migrante. Por sua vez, o encontro do agente de pastoral ancorado em um diálogo interativo com o migrante se transforma em um "lugar hermenêutico seminal" fértil na descoberta e produção de novos saberes que podem reorientar a ação teológica pastoral e a Igreja.

Para desenvolver essas noções e sua tese principal, os autores analisam depoimentos coletados junto a agentes de pastoral e funcionários do SPM; a trajetória do SPM a partir de documentos como o seu Livro de Atas (1985-2003) e os principais subsídios (texto-base, cartaz e círculos bíblicos) que orientam a Semana do Migrante e a mística da Pastoral do Migrante, além da observação participante em atividades como celebrações, encontros de grupo e atividades de campo da Pastoral do Migrante - Setor Urbanos.

Ana Cristina e Sidnei Dornelas estruturam sua análise sobre esse material tendo como ponto inicial a concepção da migração como um "fato social total". Isto é, articulada a grandes transformações sociais e culturais e que exige um conhecimento eficaz da ação do migrante na sua multiplicidade de significações sociais, culturais e religiosas.

Além disso, eles desenvolvem uma abordagem de caráter bidimensional que vai da micro a macro sociologia e da micro a macro teologia. Este caráter analítico permite, então, transitar de uma reflexão sobre a Pastoral do Migrante/ Setor Urbanos a uma reflexão sobre a Pastoral do Migrante abarcando seus três Setores de atuação (Urbanos, Imigrantes e Temporários), e, mais do que isso, descortina problemas estruturais da ação pastoral da Igreja e possibilita fazer uma reflexão sobre o conjunto das Pastorais Sociais.

\section{PARTE I - A Pastoral do Migrante e os migrantes internos na cidade de São Paulo}

O primeiro capítulo aborda o cotidiano do migrante e o diálogo com a Pastoral do Migrante. A autora aponta uma dificuldade de definição do migrante na problemática urbana que o dissolve no cotidiano fragmentado da cidade e suas questões socioculturais. A dificuldade de definição implica em dificuldades de se desenvolver um trabalho pastoral com o migrante, de encontrá-lo e estar próximo a ele. De acordo com a autora, a Pastoral do Migrante encontra dificuldades de definir com clareza o migrante e não consegue ir ao seu encontro. Haveria, então, um descompasso entre a proposta de ação pastoral e a efetiva prática do 
SPM enquanto representante da Pastoral do Migrante - Setor Urbanos.

O segundo capítulo apresenta uma abordagem sobre as relações dialéticas na atuação da Pastoral do Migrante a partir da análise de quatro pares dialéticos.

1 - Clero e leigos - este par explicita a clivagem e a presença da estrutura hierárquica da Igreja nos locais onde a Pastoral do Migrante atua. Embora o apoio da Igreja seja formal e retórico, é a figura do padre que aparece como referência de organização da ação pastoral, já que ele é o detentor da "produção" e do monopólio dos "bens sagrados" no campo religioso.

2 - Pastoral e Movimento Social - aqui aparecem uma ambiguidade e uma tensão na identidade social da Pastoral que se apresenta como Igreja de CEBs, mas assume uma agenda de temas globais e se comporta com o pragmatismo e racionalidade do movimento social.

3 - Cúpula e Base - aqui é apontado um descompasso entre as dinâmicas e estruturas do SPM e as necessidades e contingências de seus grupos de base. Isto se expressaria no distanciamento entre a cúpula e a base, bloqueando as possibilidades de renovação da primeira e tornando pouco acessível a participação dos grupos de base nas instâncias decisórias.

4 - Mística e Ideologia - aqui haveria um diálogo enviesado entre o agente de pastoral e a visão de mundo do migrante. Orientado pela definição de temas sociais que extrapolam as carências cotidianas do migrante, o agente de pastoral instrumentaliza a cultura popular em função de uma movimentação política. Ao fazer isto, ele se descola do migrante que utiliza a cultura e a religiosidade popular como meios pelos quais ele se adapta a um ambiente hostil.

Ao final, os dois autores concluem que, vivendo na tensão permanente desses quatro pares dialéticos, o SPM não implementa uma ação pastoral elementar, a escuta ao migrante. Esta ação seria contingenciada por um recrudescimento ideológico da visão de mundo do agente sobre o migrante e sua condição social. Esse recrudescimento gera um diálogo desencontrado nas relações de mediação da Pastoral do Migrante entre a Igreja e o migrante.

\section{PARTE II - O Agente de Pastoral e o Diálogo entre a Igreja e os Migrantes: Abordagem teológico-pastoral}

Expresso já no título, esta parte é a que tem uma dimensão analítica mais teológica que sociológica, muito embora esta última não se faça ausente. É também nesta parte que o caráter analítico bidimensional se expressa mais nitidamente. Além de problematizar as relações de mediação da Pastoral do Migrante, o autor elabora uma proposição de revisões teóricas e práticas dessa mediação que poderiam viabilizar a construção de um "lugar hermenêutico seminal" a partir do encontro do agente de pastoral com o migrante em sua condição social apreendida como um "lugar teológico". Este "lugar hermenêutico seminal" viabilizaria que a Igreja se aproximasse mais do migrante 
em sua condição social e se renovasse em uma nova Ecclesia cuja ação pastoral e teológica estaria emparelhada com a cultura popular e a religiosidade do migrante. Desatar-se-ia o nó do diálogo desencontrado.

No primeiro capítulo - O diálogo desencontrado entre a condição social do migrante, a Igreja e a Pastoral - o autor procura enfocar três campos distintos nos quais as relações de mediação da Pastoral do Migrante se desenvolvem - as práticas culturais dos migrantes; o cuidado pastoral da Igreja pelos migrantes; a experiência do Serviço Pastoral dos Migrantes.

A partir da análise desses três campos, procura-se mostrar que o diálogo desencontrado entre a condição social do migrante, a Igreja e a Pastoral está relacionado a uma crescente funcionalização, sistematização e pragmatismo de uma agenda que sistematicamente perderia seu caráter pastoral para buscar maior incidência sociopolítica. No entanto, essa incidência estaria desgarrada de questões locais, como a cultura, a religiosidade popular e a condição social do migrante que constitui um lugar teológico para o trabalho pastoral. No encontro do agente de pastoral com o migrante na sua condição social há a possibilidade de se criar um "lugar hermenêutico seminal". Como não ocorre esse encontro entre agente de pastoral e migrante com enfoque sobre o cotidiano deste último, o "lugar hermenêutico seminal" torna-se uma "possibilidade contingenciada".

No segundo capítulo "O Agente de Pastoral e suas Mediações" elaborase um diálogo entre a perspectiva sociológica e a teologia pastoral tendo as mediações do agente de pastoral como foco da objetivação. $\mathrm{O}$ autor observa que a forma de atuação pensada para o agente de pastoral num contexto de CEBs - Comunidades Eclesiais de Base e Teologia da Libertação que estavam presentes no nascimento da Pastoral do Migrante, embora também estivessem presentes formas de atuação política, se baseava numa interação entre o educador e o educando constituída numa relação de diálogo em que nenhuma das partes possui todo saber ou está completamente esvaziada dele. Elas procuram se educar mutuamente tendo como lugar comum o mundo a partir do qual interagem para a produção do saber, de uma consciência comum e também no sentido de uma ação comum para transformá-lo.

No entanto, o autor observa que, à margem do campo místico religioso, o agente militante não consegue dialogar com a mística religiosa do migrante que se apoia nas suas redes e condição social. Assim, a mística do agente se torna estéril teologicamente e encontra dificuldade de explicitar para o migrante a dialética da "produção da crença" na qual a fé de cada indivíduo e a crença coletiva se produzem e se condicionam simultaneamente.

O terceiro capítulo - "Em busca do diálogo entre a Igreja e os Migrantes" se apresenta como propositivo de ações teológico-pastorais. O núcleo das proposições é o "encontro" entre o agente e o migrante. Para o autor, esse 
encontro funda a Pastoral do Migrante e pode propiciar uma nova contribuição teológica para o pensamento e ação da Igreja.

A ação de escuta ao migrante permite apreender a condição social do migrante a partir de sua história de migração, seus valores e símbolos culturais e também permite apreender a definição que o migrante faz de si mesmo tornando pública sua identidade diante do interlocutor disposto a ouvi-lo. Diante disso, Sidnei Dornelas aponta que é no cotidiano das comunidades que a dinâmica do diálogo entre agentes de pastoral e leigos se realiza, que uma nova forma de experimentar a fé caminha de mãos dadas com uma nova consciência de se reconhecer como sujeito de direitos, pela possibilidade de exprimir sua palavra, seu entendimento sobre a realidade e suas condições de vida.

Todavia, a escuta não ocorreria em um espaço neutro e seus interlocutores estariam expostos a condicionamentos sociais que geram uma sensação de permanente "estranhamento" entre agentes e migrantes. Esse estranhamento poderia ser minorado a partir do respeito à irredutibilidade das alteridades dos migrantes.

Isto permitiria o surgimento de uma proposta de teologia "inter-multicultural" que toma por princípio a experiência cultural dos migrantes como um "campo" de relações em conflito. Para o autor, é no encontro entre o agente de pastoral e o migrante em sua "condição social" que a "teologia inter-multicultural" pode se desenvolver e viabilizar um "lugar hermenêutico seminal" a partir do qual a Igreja possa se renovar sob novas orientações e ações teológicopastorais apreendidas na interação entre o agente e o migrante no seu universo cultural e religioso. Se o agente de pastoral não vai ao encontro do migrante, a condição social deste como "lugar teológico" não pode ser percebida. Por conseguinte, o "lugar hermenêutico seminal" não se constrói, a Pastoral do Migrante não realiza a mediação entre os migrantes e a Igreja e esta, por conseguinte, não se transforma em nova Ecclesia.

Chegado aqui, caberia fazer três considerações a este trabalho desafiante, corajoso e polêmico:

1 - A abordagem bidimensional proporciona aos autores uma análise audaciosa, fértil e sistemática do problema proposto. Mas, também os expõe a mirar sobre largos horizontes em que aspectos relevantes da análise proposta escapam ao olhar mais inquietante, ou, nos quais os pesquisadores mais argutos são mordidos pelo objeto analítico;

2- Concebendo sociologicamente a migração como um "fato social total", a dimensão político-ideológica, característica do movimento social, não poderia ser suprimida da ação pastoral, pois o político e ideológico, juntamente com a cultura popular e a religiosidade, estão imbricados na condição social do migrante, no seu "lugar teológico". O problema não seria a concepção de uma agenda política, mas a subordinação desta agenda a uma mística teológica 
bloqueando e contingenciando as possibilidades de uma prática teológicopastoral;

3 - Na segunda parte do livro, passa-se da categoria sociológica "migração" para outra categoria sociológica "mobilidade humana" que, indubitavelmente, reporta à migração, mas necessariamente não traduz as particularidades próprias desta como um "fato social total". Nessa perspectiva, as categorias "migração" e "mobilidade humana" reclamam um discernimento teológico, sociológico e político em vista da consistente e acertada proposta de uma ação teológica "inter-multi-cultural" com o migrante a partir de sua condição social.

Por: José Carlos Alves Pereira Doutorando em Sociologia pelo IFHC-UNICAMP 